\title{
Tremor Essencial e Aspectos Psicológicos: Considerações sobre Estudos Insuficientes Associados
}

\author{
Essential Tremor and Psychological Aspects: Considerations on Associated Insufficient \\ Studies
}
Tremor Esencial y Aspectos Psicológicos: Consideraciones sobre Estudios Insuficientes Asociados

\author{
Alanny Nunes de Santana ${ }^{1}$ \\ Janaina Gaia Ribeiro Dias \\ Universidade Federal de Pernambuco (UFPE)
}

\begin{abstract}
Resumo
O tremor essencial é um distúrbio do movimento que alcança até 5\% da população mundial, vinculando-se a transtornos psiquiátricos e sofrimento psíquico. O presente artigo teve como objetivo identificar a produção científica brasileira sobre este tremor, considerando os aspectos psicológicos associados. Foi realizada uma revisão sistemática da literatura nacional publicada entre 1993 e 2018. As bases de dados consultadas foram SciELO, MEDLINE, LILACS e periódicos CAPES, a partir dos descritores "Tremor Essencial" e "Tremor and Essencial" e tradução para o inglês. A análise com 14 artigos identificou somente dois citando os aspectos psicológicos. Este tipo de investigação é pertinente, pois o impedimento na realização de movimentos impacta nas atividades diárias e de socialização. Os achados demonstraram a escassez de pesquisas nacionais que abordem diretamente esta relação, evidenciando a necessidade de maiores investimentos neste campo de estudo.
\end{abstract}

Palavras-chave: aspectos psicológicos, transtornos psiquiátricos, tremor essencial

\begin{abstract}
Essential tremor is a movement disorder that reaches $5 \%$ of the world population, linked to a psychiatric disorder and psychic suffering. The present article aimed to identify the Brazilian scientific production on this tremor, considering the associated psychological aspects. A systematic review of the national literature published between 1993 and 2018 was carried out. The databases consulted were SCIELO, MEDLINE, LILACS, and CAPES journals, from the descriptors "Tremor Essential" and "Tremor and Essential", and translation into English. The analysis with 14 articles identified only two citing the psychological aspects. This type of investigation is pertinent, since the impediment in the accomplishment of movements impacts on the daily activities and socialization. The findings demonstrated the scarcity of national surveys that directly address this relationship, evidencing the need for greater investments in this field of study.

Keywords: psychological aspects, psychiatric disorders, essential tremor.
\end{abstract}

\section{Resumen}

El temblor esencial es un trastorno del movimiento que alcanza el 5\% de la población mundial, vinculado a un trastorno psiquiátrico y el sufrimiento psíquico. El presente artículo tuvo como objetivo identificar la producción científica brasileña sobre este temblor, considerando los aspectos psicológicos asociados. Se realizó una revisión sistemática de la literatura nacional publicada entre 1993 y 2018. Las bases de datos consultadas fueron SciELO, MEDLINE, LILACS y revistas CAPES, a partir de los descriptores "Tremor Essencial" y "Tremor and Essencial", y traducción al inglés. El análisis con 14 artículos identificó solamente dos citando los aspectos psicológicos. Este tipo de investigación es pertinente, pues el impedimento en la realización de movimientos impacta en las actividades diarias y socialización. Los hallazgos demostraron la escasez de investigaciones nacionales que aborden directamente esta relación, evidenciando la necesidad de mayores inversiones en este campo de estudio.

Palabras clave: aspectos psicológicos, desórdenes psiquiátricos, temblor esencial.

\footnotetext{
${ }^{1}$ Endereço de contato: Av. da Arquitetura s/n, 80 Andar, Cidade Universitária, Recife, PE, Brasil, CEP: 50740-550. E-mail: alanny46@gmail.com
} 


\section{Introdução}

O tremor essencial (TE) é identificado como um distúrbio do movimento que afeta principalmente os membros superiores (em 95\% dos casos), sendo menos comum na cabeça (34\%), membros inferiores (20\%), voz (12\%), face (5\%) e tronco (5\%) (Shah, 2017). Pode ser definido como o tipo de tremor de maior prevalência na população mundial (Elias et al., 2016; Elble, 2017). Há evidências epidemiológicas, patológicas e genéticas de que o TE é fisiopatologicamente heterogêneo, havendo alta incidência de diagnósticos incorretos mediante dois fatores principais, sendo eles: quando o tremor nas mãos é causado por condições diversas, incluindo doença de Parkinson (DP), ou quando os demais sinais neurológicos são ignorados pelo clínico responsável (Elble, 2013).

O quadro se caracteriza por constantes oscilações voluntárias e rítmicas de partes do corpo causadas por contrações musculares, podendo ser estas contrações sincrônicas ou alternantes. Registra-se que pode acometer indivíduos de qualquer idade, atingindo de 0,08 a 220 indivíduos por 1.000 habitantes, com prevalência de até $5 \%$ na população acima de 40 anos de idade, apresentando-se constantemente como distúrbio associado à senilidade (Albuquerque, 2010; Borges, \& Ferraz, 2006). Ainda, no que tange a sua prevalência, ocorre com a frequência de 0,9\% para todas as idades, aumentando para 4\%, 4,6\% e 21,7\% em indivíduos acima dos 40, 65 e 95 anos de idade, respectivamente (Shah, 2017).

Afirma-se que em cerca de 50\% dos casos o TE é hereditário, autossômico, com início insidioso e lentamente progressivo (Troiano et al., 2004; Zeigelboim \& Mittelmann, 2008), todavia, o padrão de herança genética do distúrbio varia e pode não ser claro, conforme dados do U. S. National Library of Medicine/Genetics Home Reference de 2019². Destaca-se que há variação na intensidade do tremor sentida (medida subjetiva) por cada paciente e que este desaparece durante o sono, por se tratar de um tremor postural, e não de repouso, como o que ocorre em doenças como o Parkinson (Hubble, Busenbark, \& Koller, 1989). Ressalta-se que o TE não encurta a expectativa de vida, mas pode dificultar a execução de tarefas diárias e, consequentemente, comprometer atividades funcionais, ocasionar alterações no humor e prejudicar a socialização - fatores impactantes na qualidade de vida dos pacientes (Elias et al., 2016; Albuquerque, 2010).

Nos últimos anos, as investigações realizadas têm considerado o TE como um distúrbio complexo, heterogêneo e caracterizado por um curso progressivo, possivelmente causado por diferentes mecanismos patogênicos, com potencial comprometimento cognitivo (Medeiros et al., 2016). As avaliações neuropsicológicas de pacientes diagnosticados revelam deficits cognitivos na fluência verbal, na lembrança de palavras, nos aspectos específicos da atenção, na memória de trabalho e nas funções executivas de maneira geral (Troster et al., 2002).

Nesse contexto, considerando o impacto do TE no cotidiano dos indivíduos acometidos, é relevante considerar tanto a influência deste distúrbio do movimento nas condições psicológicas dos pacientes quanto a importância dos aspectos psicológicos dos indivíduos no prognóstico e tratamento do TE. Corroborando, entende-se que a intensidade dos tremores pode ser influenciada por aspectos como a fadiga, extremos de temperatura, estimulantes do sistema nervoso central (SNC), tabagismo e fatores emocionais (Hubble et al., 1989). Assim, sugere-se

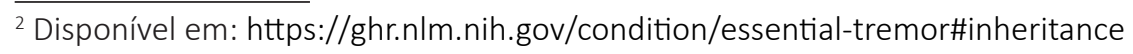


que, para além do comprometimento físico, há a possibilidade de comprometimentos não motores, entretanto, a quantidade limitada de estudos disponíveis nacional e internacionalmente não permite conclusões mais precisas ou a inferência de relações causais. Nesse sentido, pouco se sabe a respeito da influência do TE no desenvolvimento de transtornos psiquiátricos e cognitivos. Além disso, os estudos produzidos sobre a temática apresentam limitações metodológicas que incluem tamanho amostral reduzido, participantes com faixa etária limitada, ausência de comparações com grupos controle para comorbidades ou uso de drogas que possam afetar a cognição e outros transtornos psiquiátricos (Medeiros et al., 2016).

A apresentação clínica do distúrbio oferece grande variabilidade, entretanto, não está claro se esta variação se deve a subtipos distintos de $T E$, que se diferenciam quanto à etiologia, à progressão e à resposta ao tratamento (Albuquerque, 2010). Durante muitos anos, utilizou-se o termo "benigno" para designar esse tipo de tremor, todavia, na atualidade, essa denominação não é mais aplicável, tendo em vista que acaba por minimizar os impactos e a incapacidade gerada pelo TE em um grande número de pacientes acometidos (Zeigelboim \& Mittelmann, 2008). Desse modo, objetiva-se, com o presente artigo, apresentar uma revisão da literatura nacional com meta-análise a respeito do TE, destacando as principais temáticas em foco nos estudos publicados sobre este distúrbio do movimento. Enfatizou-se, na análise dos artigos, se as pesquisas sobre o TE destacaram ou não os aspectos psicológicos como relevantes, tanto no contexto dos diagnósticos quanto nos tratamentos disponíveis para o distúrbio. A partir desta revisão, é possível identificar lacunas existentes sobre a temática, com destaque para os aspectos psicológicos e a ênfase na relevância de novas pesquisas neste campo de estudo.

\section{Método}

O presente artigo se trata de uma revisão sistemática da literatura com meta-análise de caráter exploratório e descritivo, permitindo ao leitor uma maior familiaridade com o tema abordado e com suas características centrais, visto que este é ainda pouco conhecido e explorado, especialmente no campo da psicologia. Para tanto, foram seguidas as etapas sugeridas por Cooper (2015) acerca dos sete estágios de planejamento de uma meta-análise, expressas no fluxograma da Figura 1.

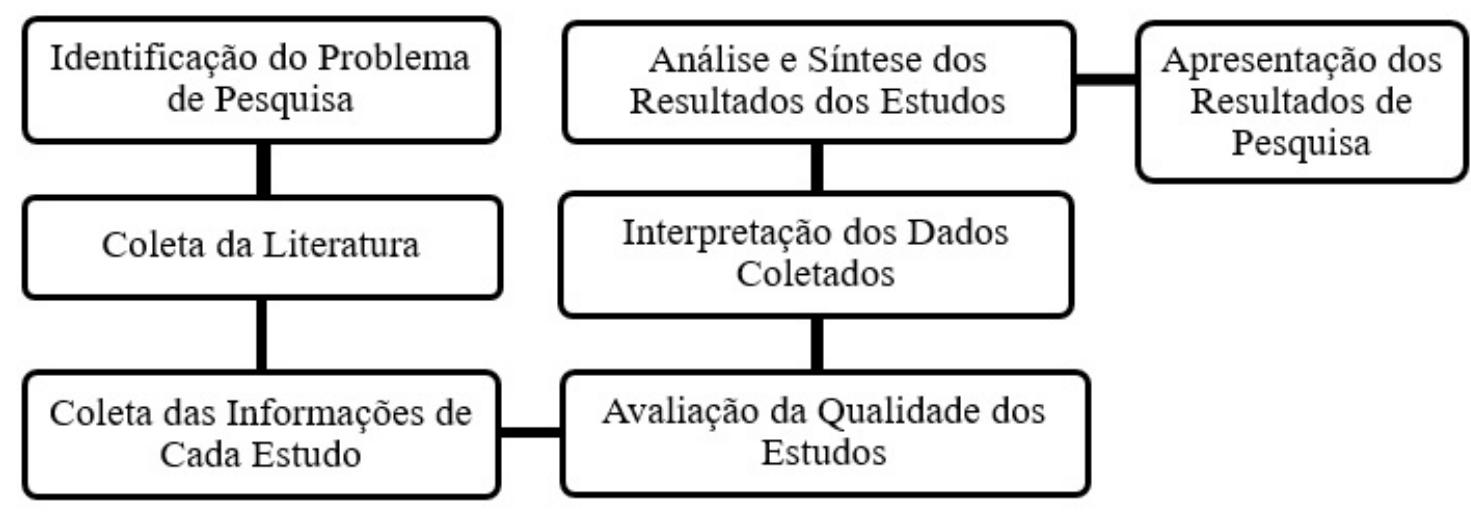

Figura 1. Fluxograma dos estágios de planejamento da meta-análise.

Considerou-se, para efeito deste estudo, a seguinte pergunta de pesquisa: a literatura nacional apresenta dados que permitam inferências relativas à conjunção entre o TE e aspectos 
psicológicos? Para a coleta de dados, empreendeu-se uma pesquisa bibliográfica por textos que abordassem o tema, nas bases de dados Scientific Electronic Library Online (SciELO), Medical Literature Analysis and Retrieval System Online (MEDLINE), Literatura LatinoAmericana e do Caribe em Ciências da Saúde (LILACS) e nos periódicos disponíveis no site da Coordenação de Aperfeiçoamento de Pessoal de Nível Superior (CAPES). Destaca-se que, no intuito de não limitar a busca realizada, não foram selecionados demarcadores temporais, incluindo estudos publicados até o ano de 2018, objetivando encontrar o maior número possível de artigos disponíveis on-line.

A partir da definição e caracterização dos constructos analisados, bem como a disponibilidade no banco de terminologias BVS Psicologia, foram utilizados os seguintes descritores: "Tremor Essencial" e "Tremor and Essencial". Estes também foram utilizados em língua inglesa, objetivando novamente não limitar o número de estudos incluído. Registra-se que, apesar do objetivo tratar do TE e sua relação com aspectos psicológicos, não foram identificados artigos ao inseri-los nos mecanismos de busca, sugerindo aparente inexistência de pesquisas nacionais publicadas, as quais se centrem especificamente nesta relação.

Na presente revisão, foram incluídos somente artigos que 1) fazem referência direta ao tema "tremor essencial"; 2) em língua portuguesa e inglesa e 3) que apresentam pesquisas realizadas no Brasil. Estudos coincidentes em duas ou mais fontes foram contabilizados apenas uma vez e aqueles que não disponibilizaram texto completo e/ou gratuitamente disponível, após tentativas de contato sem sucesso com os autores, foram excluídos da análise. Os artigos que se enquadraram nos requisitos apresentados foram inicialmente selecionados a partir dos seus resumos e armazenados com o auxílio da ferramenta Microsoft Excel. Aqueles que se adequaram foram revisados na íntegra.

Considerando os critérios de inclusão e exclusão, a amostra de textos foi composta por 14 artigos, sendo considerados aspectos específicos para a coleta de informações, tais como: 1) ano de publicação; 2) tipo de estudo empreendido; 3) revista publicada, 4) tema analisado e 5) presença ou não de aspectos psicológicos. A análise, síntese e interpretação dos resultados foram realizadas explorando especialmente as lacunas, semelhanças e diferenças entre os estudos, apreciando as cinco categorias supracitadas. Levando em consideração o pequeno tamanho da amostra de artigos localizada, optou-se por realizar apenas análises estatísticas de frequência. Na próxima seção, serão apresentados os resultados da análise das pesquisas incluídas.

\section{Resultados}

A busca nas bases de dados resultou na localização de 197 artigos potencialmente relevantes; todavia, após as análises realizadas, foram removidos 183 estudos por não atenderem aos critérios de inclusão referidos no método, conforme apresenta a Figura 2. 


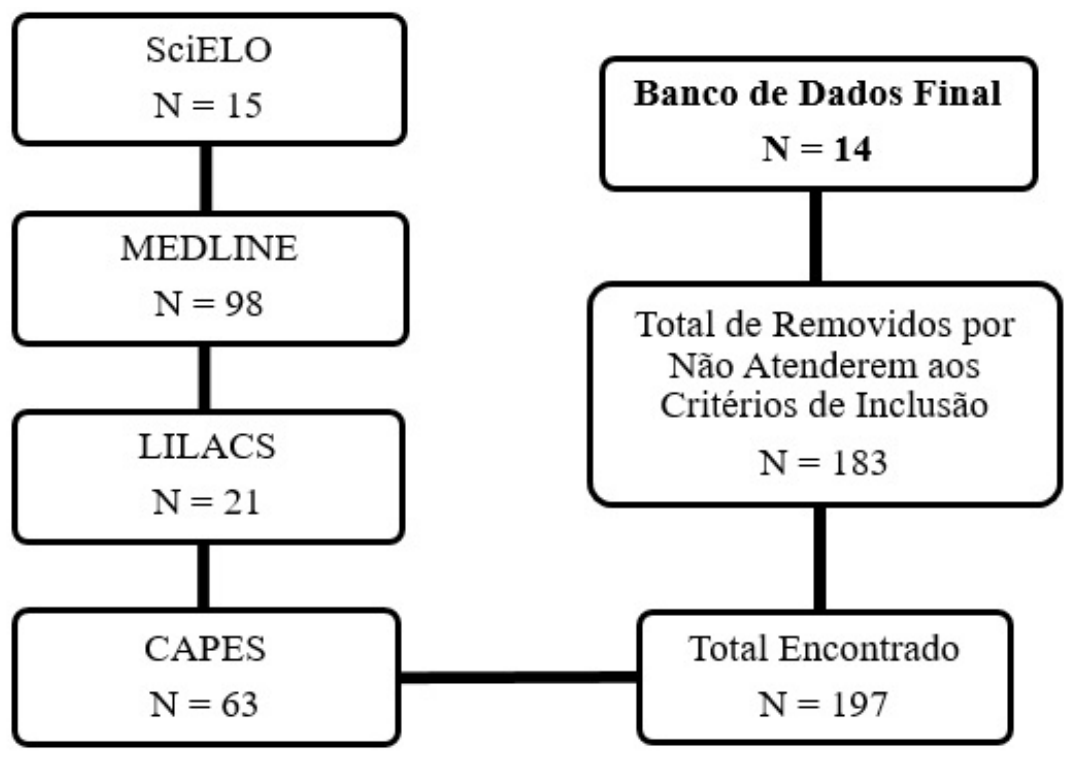

Figura 2. Resultado da busca nas bases de dados.

O levantamento resultou na análise de 14 artigos publicados nas seguintes revistas: Arquivos de Neuro-Psiquiatria (B1), Associação Brasileira de Otorrinolaringologia e Cirurgia Cérvico-Facial (B2), Cadernos de Saúde Pública (A1), Jornal Brasileiro de Psiquiatria (A2), Radiologia Brasileira (B2), Revista Neurociências (B2) e Revista CEFAC (B2). Mediante a observação dos estratos de classificação, é possível verificar que há periódicos na área de Psicologia com Qualis CAPES A1, A2, B1 e B2, indicando a qualidade e relevância dos estudos analisados. A partir da identificação das revistas, é possível inferir que nenhuma delas é da área da psicologia, sendo evidenciadas as que publicam estudos majoritariamente da área médica.

No que se refere ao ano de publicação dos estudos, observaram-se pesquisas que datam do início dos anos 1990 (1993 e 1994), bem como pesquisas contemporâneas referentes aos anos de 2016 e 2017

A frequência de publicações sobre o tema é limitada, considerando-se que este estudo não realizou demarcações temporais na sua busca por artigos. Os anos que apresentaram mais trabalhos foram os de 1994 e 2016, com a publicação de dois estudos por ano (Borges, Ferraz, \& Andrade, 1994; Moraes \& Biase, 2016; Medeiros et al., 2016). A Tabela 1 apresenta a descrição dos artigos que foram incluídos e analisados nesta revisão, demonstrando seus títulos, autores e anos de publicação das pesquisas.

Tabela 1.

Descrição dos Estudos Incluídos

\begin{tabular}{llc}
\hline \multicolumn{1}{c}{ Títulos } & \multicolumn{1}{c}{ Autores } & Ano \\
\hline Tremor essencial: observações clínicas & Pereira, Pimentel, \& Nicaretta & 1993 \\
\hline $\begin{array}{l}\text { Tremor essencial: caracterização clínica de uma } \\
\text { amostra de 176 pacientes }\end{array}$ & Borges, Ferraz, \& Andrade & 1994 \\
\hline $\begin{array}{l}\text { Tremor postural e distonia: aspectos clínicos e } \\
\text { considerações fisiopatológicas }\end{array}$ & $\begin{array}{l}\text { Ferraz, Andrade, Azevedo Silva, } \\
\text { Borges, \& Rocha }\end{array}$ & 1994 \\
\hline
\end{tabular}




\begin{tabular}{lll}
\hline \multicolumn{1}{c}{ Títulos } & \multicolumn{1}{c}{ Autores } & Ano \\
\hline $\begin{array}{l}\text { Estimulação cerebral contínua (DBS) talâmica } \\
\text { para controle do tremor }\end{array}$ & $\begin{array}{l}\text { Nasser, Falavigna, Alaminos, } \\
\text { Bonatelli, \& Ferraz }\end{array}$ & 2002 \\
\hline $\begin{array}{l}\text { Uso do propranolol de ação prolongada em 40 } \\
\text { pacientes com tremor essencial e virgens de } \\
\text { tratamento }\end{array}$ & $\begin{array}{l}\text { Troiano, Teive, Fabiani, Zavala, Sá, } \\
\text { Germiniani, Camargo, \& Werneck }\end{array}$ & 2004 \\
\hline Avaliação vestibular no tremor essencial & Zeigelboim \& Mittelmann & 2008 \\
\hline Olfaction and essential tremor & Quagliato, Viana, Quagliato, \& Simis & 2009 \\
\hline Tremor essencial & Albuquerque & 2010 \\
\hline $\begin{array}{l}\text { Achados de ultrassonografia transcraniana na } \\
\text { doença de Parkinson e no tremor essencial: } \\
\text { relato de casos }\end{array}$ & $\begin{array}{l}\text { Fernandes, Rosso, Vincent, Bahia, } \\
\text { Resende, \& Araujo }\end{array}$ & 2012 \\
\hline $\begin{array}{l}\text { Cessação tabágica em paciente com tremor } \\
\text { essencial }\end{array}$ & Costa, Cotrik, Araújo, \& Brasil & 2013 \\
\hline $\begin{array}{l}\text { Electrophysiologic characteristics of tremor in } \\
\text { Parkinson's disease and essential tremor }\end{array}$ & $\begin{array}{l}\text { Cichaczewski, Munhoz, Maia, } \\
\text { Nohama, Nóvak, \& Teive }\end{array}$ \\
\hline $\begin{array}{l}\text { Protocolo de avaliação laringoscópica para } \\
\text { diferenciação de tremor vocal essencial e distônico }\end{array}$ & Moraes \& Biase \\
\hline $\begin{array}{l}\text { Patients with essential tremor can have } \\
\text { manual dexterity and attention deficits with no } \\
\text { impairments in other cognitive functions }\end{array}$ & Medeiros et al. \\
\hline $\begin{array}{l}\text { Tremor essencial em guardas de endemias } \\
\text { expostos a agrotóxicos: estudo caso-controle }\end{array}$ & Azevedo \& Meyer \\
\hline
\end{tabular}

Quanto ao tipo de estudo empreendido pelos autores, destacam-se os relatos de casos (Azevedo \& Meyer, 2017; Costa, Cotrik, Araújo, \& Brasil, 2013; Fernandes et al., 2012; Zeigelboim \& Mittelmann, 2008), especialmente de caso único (36\% das pesquisas). Foram verificados também estudos de revisão bibliográfica (Albuquerque, 2010) e revisão de prontuários (Borges et al., 1994), correspondendo a 18\% das pesquisas incluídas, além de três estudos comparativos e um estudo de intervenção (Troiano et al., 2004).

O tema mais analisado nos estudos foi referente aos aspectos/caracterização clínica do TE (58\%), seguido do diagnóstico do quadro e sua avaliação diferencial (14\%), do tratamento (14\%), do tabagismo (7\%) e da exposição a agrotóxicos (7\%). Tratando-se dos aspectos psicológicos explorados pelos autores na relação dos pacientes com o TE, enfatiza-se que em apenas um dos estudos estes foram citados (Costa et al., 2013). Na próxima seção, será apresentada a discussão referente aos resultados verificados.

\section{Discussão}

Ao considerar a amplitude de textos abarcada pelos descritores utilizados, é possível afirmar que a literatura sobre o TE ainda é escassa. Diante do distúrbio do movimento mais diagnosticado na população (Hubble et al., 1989), a localização de apenas 14 estudos nacionais indica a necessidade de se empreender mais pesquisas sobre o TE.

No que tange ao ano de publicação dos estudos analisados, é possível inferir que a temática é mais investigada no século XXI, ao se comparar com períodos anteriores, na medida em que 11 dos 14 artigos foram produzidos nos últimos 17 anos (entre 2002 e 2018). Entretanto, faz-se necessário o aumento no número de publicações científicas sobre o TE, tendo em vista 
que este distúrbio ainda não apresenta causa definida nem terapêuticas curativas. Os estudos disponíveis nem sequer apresentam seguramente uma caracterização clínica generalizável ou mesmo os fatores que podem ser considerados preditores do TE. Este distúrbio é geralmente associado à senilidade e pode também ser classificado de diversas maneiras, conforme a sua etiologia, fenomenologia, frequência ou localização (Borges \& Ferraz, 2006).

Nesse sentido, os estudos que tratam sobre a origem do distúrbio afirmam que os mecanismos fisiopatológicos responsáveis pela gênese do TE ainda não são totalmente esclarecidos, sem identificar possível doença ou lesão estrutural específica no SNC relacionada à origem do tremor (Zeigelboim \& Mittelmann, 2008). A partir dos estudos de neuroimagem funcional, nota-se a hipótese sobre a influência do aumento da utilização de glicose no núcleo olivar inferior, assim como o aumento de fluxo sanguíneo no cerebelo, núcleo rubro e tálamo (Troiano et al., 2004; Zeigelboim \& Mittelmann, 2008).

Quanto aos estudos genéticos, demonstram pelo menos dois locais fixos em cromossomos (loci) que podem estar implicados na gênese do TE nas suas formas autossômicas dominantes, sendo os principais genes localizados em 3q132 e 2p222 (Troiano et al., 2004). A respeito da influência da genética no TE, Jiménez-Jiménez et al. (2013) afirmam que estudos genéticos de ligação identificaram três genes em um número baixo de famílias aparentemente autossômicas dominantes com TE; entretanto, estes genes explicam somente uma porcentagem mínima de sua hereditariedade. Desse modo, até o momento, a literatura aponta que há entre dois (Troiano et al., 2004) e três (Albuquerque, 2010; Jiménez-Jiménez et al., 2013) loci cromossômicos relacionados ao TE, sendo o principal diagnóstico diferencial o parkinsonismo.

Associações do TE com a presença de genes com mutação e com outras doenças degenerativas, tais como a distonia de torção idiopática, não foram encontradas. Uma revisão de pesquisas realizadas em famílias com tremor, estudos com gêmeos, estudos de associação, caso-controle e sequenciamento identificou que, entre os diversos estudos de associação caso-controle, apenas variantes do gene LINGO1 parecem aumentar modestamente o risco de TE em pacientes com história familiar. Para além dos estudos em genética, apontou-se ainda o tabagismo e a exposição a agrotóxicos como importantes influenciadores no contexto de apresentação dos tremores posturais (Jiménez-Jiménez et al., 2013).

Um dos estudos analisados destaca diferentes aspectos relacionados à origem e à caraterização clínica do TE (Azevedo \& Meyer, 2017). Regiões cerebrais específicas são enfatizadas, tais como: 1) as áreas motoras 4 e 6 de Brodmann, associadas à posição e ao movimento corporal; 2) os circuitos córtico-estriado-tálamo-cortical e 3) o circuito córtico-ponto-cerebelo-rubro-cortical; 4) o triângulo de Guillain-Mollaret, responsável pelas bases fisiológicas do tônus muscular, equilíbrio e coordenação motora; 5) as alterações histopatológicas na região cerebelar e 6) no tronco cerebral; e 7) os neurotransmissores ácido gama-amino-butírico (GABA), acetilcolina, dopamina e o ácido glutâmico (Azevedo \& Meyer, 2017).

No que tange aos tipos de estudos publicados sobre o TE e incluídos nesta revisão, destacam-se os estudos de casos clínicos. Nesse contexto, Azevedo e Meyer (2017) realizaram um estudo de caso-controle, ao avaliarem a influência da exposição aos agrotóxicos sobre o desenvolvimento deste tipo de tremor em 442 guardas de endemias do estado do Rio de Janeiro. Os resultados evidenciaram que o tempo de aplicação de agrotóxicos pode estar as- 
sociado ao desenvolvimento de TE nessa categoria profissional, revelando a importância de atentarmos ao impacto da aplicação de agrotóxicos para o desenvolvimento desse distúrbio. Outro estudo de caso, desenvolvido por Costa et al. (2013), apresenta um caso único de TE e comorbidades psiquiátricas sofridas pelo paciente no seu percurso de abstinência tabágica.

Também como um estudo de caso único, a pesquisa desenvolvida por Zeigelboim e Mittelmann (2008) apresenta a avaliação de uma paciente com história de tremor na cabeça. A partir da realização de anamnese, inspeção otológica e avaliação vestibular por meio da vectoeletronistagmografia, os autores concluem que o exame vestibular se mostra sensível e importante para captar alterações no SNC, representando uma relevante ferramenta diagnóstica do TE.

Nesta mesma direção, Fernandes et al. (2012) realizaram um estudo de caso clínico, especificamente de quatro casos, dois de pacientes com TE e dois de pacientes com a doença de Parkinson. Neste estudo, os autores utilizaram a ultrassonografia transcraniana como ferramenta diagnóstica que permite o diagnóstico diferencial entre as duas doenças. Como resultados do estudo, os autores destacam que a ultrassonografia transcraniana permite sugerir o diagnóstico para doenças do movimento, apesar de apresentar limitações relacionadas à dependência de janela óssea e à baixa especificidade.

Foram encontrados ainda estudos de revisão bibliográfica (Albuquerque, 2010) e de revisão de prontuários (Borges et al., 1994), além de estudos comparativos (Pereira, Pimentel, \& Nicaretta, 1993) e estudos de intervenção (Troiano et al., 2004). Quanto aos dois estudos de revisão encontrados nas buscas, destaca-se que ambos enfatizaram o fato de não haver uma caracterização clínica bem delimitada do distúrbio. Borges et al. (1994), ao revisarem os registros de 176 pacientes com TE quanto à história familiar, às características do tremor, à distribuição anatômica e à idade de início dos sintomas, verificaram que a história familiar de tremor foi encontrada em $47,2 \%$ da amostra analisada, sendo o acometimento isolado das mãos a forma de manifestação mais frequente.

Os autores afirmam que os tremores de ação e de postura apareceram combinados em 49,4\% dos casos, não havendo diferenças clínicas significativas entre os grupos com tremor de origem familiar e o grupo com tremor sem história familiar. A partir da revisão de prontuários realizada, eles inferiram que o acometimento isolado das mãos foi mais frequente entre pessoas do sexo masculino, enquanto o tremor de cabeça foi predominante no sexo feminino. A idade de início do aparecimento dos tremores variou de 4 a 85 anos, mostrando-se significantemente menor nos pacientes do sexo masculino com história familiar (36,5 anos) e, também, nos pacientes com tremor de ação e postural combinados de mesmo sexo. Além disso, os autores destacaram que a idade de início não foi diferente quando se compararam grupos de pacientes com parentes de primeiro grau acometidos (Borges et al., 1994).

Albuquerque (2010), ao empreender uma revisão da literatura, verificou que na atualidade há fortes evidências de que o TE é um distúrbio heterogêneo e lentamente progressivo, o qual pode causar importante diminuição da qualidade de vida de alguns pacientes que o portam. Na referida revisão, foi enfatizado que pode ocorrer de forma esporádica ou com padrão familiar, em consonância com os dados encontrados na revisão de Borges et al. (1994).

Quanto aos estudos comparativos, identifica-se novamente a caracterização clínica do TE, assim como nos estudos teóricos. Pereira et al. (1993) analisaram 53 casos no Ambulatório de Distúrbios do Movimento do Hospital Universitário Pedro Ernesto, da Universidade do 
Estado do Rio de Janeiro (UERJ), quanto à história familiar, ao sexo, à idade e às áreas de acometimento corporal. Os autores verificaram que apenas 37,7\% apresentavam história familiar para TE, sendo a maioria dos pacientes advinda de famílias sem histórico da doença. Quanto ao sexo, observaram o predomínio do sexo feminino $(56,60 \%)$ em relação ao masculino $(43,40 \%)$, ressaltando, ainda, a maior frequência em pessoas da raça branca $(69,80 \%)$.

Já nos dados verificados por Borges et al. (1994), houve maior acometimento entre pessoas do sexo masculino. Para a faixa etária, os achados de Pereira et al. (1993) revelaram maior incidência da doença após os 50 anos de idade, predominando entre os 60 e 70 anos. Os autores ressaltam ainda que as mãos foram a parte do corpo mais acometida pelo TE (96,20\%), prevalecendo sobre as demais áreas corporais, como o encéfalo (28,30\%), a voz $(16,99 \%)$, as pernas (11,30\%), a língua (3,78\%) e o tronco (1,88\%). Além disso, observou-se, em consonância com o que afirmam Borges et al. (1994), que os tremores apareciam combinados, dificilmente revelando-se de forma isolada em uma só parte do corpo do paciente.

$\mathrm{Na}$ discussão sobre os temas mais analisados nos estudos, destacam-se as pesquisas referentes à caracterização clínica do TE. Nesse sentido, afirma-se que costuma acometer as mãos e os antebraços dos indivíduos, podendo ou não acometer ambas as mãos, manifestando-se também em outras partes do corpo, como a cabeça (Azevedo \& Meyer, 2017; Zeigelboim \& Mittelmann, 2008), e provocando alterações na emissão vocal em $11 \%$ a 30\% dos casos (Moraes \& de Biase, 2016). Observa-se ainda que a constância dos tremores varia entre $4 \mathrm{~Hz}$ e $12 \mathrm{~Hz}$, tendo evolução lenta durante os anos e apresentando comorbidades associadas (Azevedo \& Meyer, 2017).

Afirma-se que o TE pode ocorrer em indivíduos de qualquer idade, sendo mais frequente após os 40 anos, igualmente entre homens e mulheres. Conforme a pesquisa de Pereira et al. (1993), a média de idade de início dos tremores nos pacientes variou de 4 a 85 anos, enquanto em outros estudos essa média variou de 35 a 50 anos. Dos pacientes avaliados nesta pesquisa, poucos apresentaram TE antes dos 10 anos de idade, afirmando-se que o distúrbio raramente é diagnosticado antes da adolescência, comumente surgindo após os 60 anos de idade (Pereira et al., 1993).

Nas pesquisas que abordaram o tema diagnóstico, foi enfatizada a importância da diferenciação entre o TE e a doença de Parkinson, entendendo-se como critério de diagnóstico diferencial o tipo de tremor, que na doença de Parkinson é de repouso e no TE é postural. Nesse sentido, Cichaczewski et al. (2014) apontam que os tremores observados em ambas as condições costumam apresentar perfis eletrofisiológicos específicos, embora a amplitude e a frequência possam ter grandes variações. Os autores destacam que a análise do tremor em si não é capaz de diferenciar individualmente os casos de TE e DP, especialmente se for considerada apenas a frequência como variável diferenciada.

Destaca-se também a importância do diagnóstico individualizado entre o TE e o tremor fisiológico, comum a todas as pessoas em situações que causem estresse, ansiedade e fadiga (Borges \& Ferraz, 2006). Há ainda o tremor ortostático como variante do TE, caracterizado por baixa amplitude e frequência e cujo início ocorre após o indivíduo adquirir a posição ortostática. Destaca-se que a avaliação de um paciente com tremor deve incluir uma adequada e detalhada história clínica, exames físicos e, em certos casos, exames complementares (Albuquerque, 2010). 
O TE ainda continua sendo um quadro neurológico de diagnóstico eminentemente clínico, entretanto, a tomografia por emissão de pósitrons, a espectroscopia cerebelar por ressonância magnética, a ultrassonografia transcraniana, a eletroneuromiografia e o acelerômetro são também utilizados como critérios diagnósticos. Contudo, ainda se afirma que estes métodos não são capazes de predizer especificamente o diagnóstico do TE (Azevedo \& Meyer, 2017).

Quanto ao tratamento, opções disponíveis são a mudança de hábitos de vida, abordagem farmacológica (tradicionalmente, o propranolol e a primidona), a quimio de nervação com toxina botulínica, as medidas físicas e psicológicas, bem como o tratamento cirúrgico (Troiano et al., 2004; Zeigelboim \& Mittelmann, 2008). Enfatiza-se ainda que são percebidas melhoras nos tremores com a ingestão de álcool e de drogas betabloqueadoras (Pereira et al., 1993). Destacou-se que as drogas para o tratamento ainda se restringem, na maioria dos casos, ao propranolol e à primidona, mas que a gabapentina, o topiramato e o alprazolam são opções terapêuticas, assim como a cirurgia nos casos de maior gravidade e incapacitação do paciente (Albuquerque, 2010).

O estudo de intervenção realizado por Troiano et al. (2004) tratou do uso de medicamento para o tratamento do TE, relatando a administração do propranolol de ação prolongada em 40 pacientes sem tratamentos anteriores. A partir das avaliações dos tremores antes e depois da intervenção medicamentosa, Troiano verificou que, dos 40 indivíduos avaliados, $82,5 \%$ apresentaram algum grau de melhora com o uso do medicamento e em 52,5\% da amostra a melhora foi considerada ótima ou boa. Desse modo, a partir do estudo, pôde-se concluir que a administração do propranolol mostrou ser adequada para o tratamento.

A estimulação cerebral profunda talâmica é apontada também como uma forma de tratamento, permitindo o ajuste dos parâmetros elétricos e o controle adequado do tremor (Nasser, Falavigna, Alaminos, Bonatelli, \& Ferraz, 2002). Ao avaliar o uso do propanolol de ação prolongada, verificaram-se melhores efeitos na redução dos tremores de mãos, de cabeça, voz ou variantes. Entretanto, verificam-se efeitos colaterais associados ao uso da medicação, tais como: fraqueza muscular, disfunção erétil, náusea, ganho de peso e depressão (Troiano et al., 2004).

No que se refere aos aspectos psicológicos explorados pelos autores na relação dos pacientes com o TE, enfatiza-se que em apenas dois dos estudos estes foram citados diretamente. Nesse contexto, foram registrados pensamentos de desesperança, a piora da autoestima e o aumento da fissura tabágica associados à apresentação de tremor de repouso postural e de ação grosseiros. Estes aspectos psicológicos estão associados ao impedimento na realização de movimentos finos no cotidiano do sujeito acometido (Costa et al., 2013).

Em seu estudo, Costa et al. (2013) citam o TE como um dos motivos relacionados à resistência de pacientes à redução do tabagismo. Destaca-se que o TE, frequentemente negligenciado pelos pacientes e médicos por ser considerado benigno, tem implicações clínicas diretas e indiretas para aqueles que desejam parar de fumar, tendo em vista que o TE tem fortes associações com transtornos psiquiátricos, além de piorar com a abstinência de nicotina e com o uso de determinados medicamentos para a cessação tabágica. Nesse sentido, os autores ressaltam a importância de nos atentarmos ao TE como um distúrbio que não pode mais ser entendido como benigno, já que impacta diretamente a vida dos pacientes acometidos. No estudo empreendido por Medeiros et al. (2016), ressaltam-se as correlações do TE com sintomas de depressão e ansiedade, destacando-se, também, que pessoas com TE e sintomas depressivos e ansiosos demonstram maior pobreza manual e menor performance cognitiva. 
Desse modo, considera-se que o TE não pode mais ser visto como uma entidade meramente benigna e monossintomática (Zeigelboim \& Mittelmann, 2008). Este distúrbio apresenta fortes associações com transtornos psiquiátricos (Costa et al., 2013), assim como pode ser piorado pela influência de fatores, tais como a ansiedade e o estresse emocional (Troiano et al., 2004). Apesar de não tratar especificamente de aspectos psicológicos, um dos estudos afirma ainda que existem associações entre o TE e alterações cognitivas e transtornos de humor (Azevedo \& Meyer, 2017). Assim, podemos entender a relevância e a demanda pelo desenvolvimento de pesquisas que abordem diretamente a relação entre aspectos psicológicos e TE, pois este distúrbio implica diretamente o sofrimento psíquico dos indivíduos.

De acordo com a Associação Brasileira de Psiquiatria (2011), a presença de doenças pode representar um maior risco de desenvolvimento do Transtorno da Ansiedade Social (TAS), como um medo acentuado e persistente de situações sociais ou de desempenho, a exemplo de falar em público. Nesse sentido, o quadro de TE pode representar um possível influenciador no desenvolvimento da TAS, já que indivíduos com TE apresentam dificuldades na realização de movimentos que exijam a coordenação motora fina, tais como escrever, o que pode levá-los a apresentar quadros de estresse e de ansiedade diante de situações sociais que demandem a realização dessas atividades.

Em estudo realizado por Boing et al., (2012), foram identificadas as associações entre doenças crônicas e a depressão. Os autores afirmam que a prevalência da depressão é expressivamente mais elevada nestes casos, sendo possível configurar esse grupo como de especial atenção por parte de profissionais da área da saúde e dos formuladores de políticas públicas. Além disso, os autores alertam sobre indivíduos com quadro de doenças que implicam limitações na sua vida diária, os quais apresentam maior probabilidade para o diagnóstico de depressão. Ainda nesse sentido, afirma-se que os problemas relacionados às restrições diárias podem levar também ao desenvolvimento de transtornos do humor. Ao definir o TE como uma desordem de natureza crônica, a qual acarreta restrições no desenvolvimento de atividades diárias, compreende-se este distúrbio como um dos fatores de maior influência no desenvolvimento de transtornos depressivos e de humor (Leite, 2010).

Pela inexistência de estudos específicos, não podemos ter a completa clareza a respeito da influência do TE no desenvolvimento dos transtornos de ansiedade generalizada, de ansiedade social, de transtornos depressivos e até mesmo acerca da influência dos tremores nos casos de ideação suicida e suicídio. Entretanto, é possível inferir que os comprometimentos gerados pelo distúrbio ou mesmo pelos efeitos colaterais dos tratamentos do TE são relevantes e produzem resultados diretos na vida particular e social dos indivíduos. Na próxima seção, será apresentada a conclusão referente aos resultados e à discussão empreendida neste artigo.

\section{Considerações Finais}

O TE é o distúrbio do movimento mais frequente na população mundial, todavia, são poucos os estudos nacionais que se centram especificamente neste quadro clínico. Desse modo, ainda não estão bem estabelecidas as suas causas, a melhor forma de diagnóstico ou mesmo o tratamento para a eliminação ou redução dos tremores posturais. Assim, entende-se que esta condição permanece com esclarecimentos limitados, mesmo diante de significativos impedimentos no cotidiano dos pacientes acometidos. 
Nesse âmbito, ao apresentar a análise dos 14 estudos nacionais indexados nas bases de dados SciELO, MEDLINE, LILACS e nos periódicos CAPES, este artigo explana sobre a limitação dos estudos na área, bem como sobre a falta de dados conclusivos e amplamente generalizáveis sobre este distúrbio. Para além das considerações a respeito da sintomatologia, diagnóstico e tratamento, visou-se, com este artigo, abordar os aspectos psicológicos associados ao TE, percebendo-se que apenas dois dos estudos analisados os citaram diretamente. Nesse ínterim, os demais estudos incluídos não fizeram referência à influência do TE nos aspectos psicológicos dos sujeitos acometidos por este distúrbio, nem vice-versa. Assim, há uma grande lacuna na atualidade referente ao tema, o qual se apresenta sem investimentos empíricos e teóricos pelo campo da psicologia.

Desse modo, é relevante a realização de pesquisas que abordem a conjunção entre o TE e os aspectos psicológicos dos indivíduos que o apresentam, tendo em vista que o impedimento na realização de movimentos finos no dia a dia impacta significativamente as capacidades de socialização e o humor. Além disso, avaliações sistemáticas, como as neuropsicológicas, auxiliam na realização de novas investigações, explorando vias que identifiquem e intervenham na difusão científica com grupos clínicos específicos, resultando em diagnósticos mais amplos e detalhados quanto às diferenças individuais para os deficits apresentados e contribuindo para o desenvolvimento de estratégias interventivas baseadas em evidências. Destaca-se que este estudo apresenta limitações no que se refere às bases de dados consultadas e aos idiomas selecionados na busca. Futuras investigações poderão ampliar os achados sobre o tema, incluindo pesquisas em outros idiomas, assim como teses e dissertações sobre a temática.

\section{Referências}

Albuquerque, A. V. (2010). Tremor Essencial. Revista Neurociências, 18(3), 401-405. Recuperado de http://www.revistaneurociencias.com.br/edicoes/2010/RN1803/377\%20 revisao.pdf

Associação Brasileira de Psiquiatria \& Sociedade Brasileira de Medicina de Família e Comunidade. (2011). Transtorno da Ansiedade Social: Diagnóstico. Diretrizes Clínicas na Saúde Suplementar. São Paulo: AMB/ANS. Recuperado de http://diretrizes.amb.org.br/ ans/transtorno_da_ansiedade_sociedade_social-diagnostico.pdf

Azevedo, M. F. A., \& Meyer, A. (2017). Tremor essencial em guardas de endemias expostos a agrotóxicos: Estudo caso-controle. Cadernos de Saúde Pública, 33(8), 1-12. doi: http:// dx.doi.org/10.1590/0102-311x00194915

Boing, A. F., Melo, G. R., Boing, A. C., Moretti-Pires, R. O., Perez, K. G., \& Perez, M. A. (2012). Associação entre depressão e doenças crônicas: Um estudo populacional. Revista Saúde Pública, 46(4), 617-623. doi: http://dx.doi.org/10.1590/S0034-89102012005000044

Borges, V., \& Ferraz, H. B. (2006). Tremores. Revista Neurociências, 14(1), 43-47. Recuperado de http://www.revistaneurociencias.com.br/edicoes/2006/RN\%2014\%2001/Pages\%20 from\%20RN\%2014\%2001-7.pdf

Borges, V., Ferraz, H. B., \& Andrade, L. A. F. (1994). Tremor essencial: Caracterização clínica de uma amostra de 176 pacientes. Arquivos Neuro-Psiquiatria., 52, 161-165. doi: http:// dx.doi.org/10.1590/S0004-282X1994000200005 
Cichaczewski, E., Munhoz, R. P., Maia, J. M., Nohama, P., Nóvak, E. M., \& Teive, H. A. (2014). Electrophysiologic characteristics of tremor in Parkinson's disease and essential tremor. Arquivos de Neuro-Psiquiatria, 72(4), 301-306. doi: http://dx.doi. org/10.1590/0004-282X20140006

Cooper, H. (2015). Research synthesis and meta-analysis: A step-by-step approach (3a ed.). Thousand Oaks, CA: Sage.

Costa, C. F., Cotrik, E., Araújo, A., \& Brasil, M. A. (2013). Cessação tabágica em paciente com tremor essencial. Jornal Brasileiro de Psiquiatria, 62(1),85-8. doi: http://dx.doi. org/10.1590/S0047-20852013000100012

Elble, R. J. (2013). What is Essential Tremor? Current Neurology and Neuroscience Reports, 13(353). doi: http://doi.org/10.1007/s11910-013-0353-4

Elble, R. J. (2017). Tremor. In Tousi B., Cummings J. (Eds.), Neuro-Geriatrics (pp 311-326). [s.l.]: Springer. Recuperado de: http://link.springer.com/ chapter/10.1007/978-3-319-56484-5_20

Elias, W. J., Lipsman, N., Ondo, W. G., Ghanouni, P., Kim, Y. G. Lee, W., . . Chang, J. W. (2016). A Randomized Trial of Focused Ultrasound Thalamotomy for Essential Tremor. The New England Journal of Medicine, 375, 730-739. doi: http://doi.org/10.1056/NEJMoa1600159

Fernandes, R. C. L., Rosso, A. L. Z., Vincent, M. B., Bahia, P. R. V., Resende, C. M. C., \& Araujo, N. C. (2012). Achados de ultrassonografia transcraniana na doença de Parkinson e no tremor essencial: Relato de casos. Radiologia Brasileira, 45(6), 356-358. doi: http://dx.doi. org/10.1590/S0100-39842012000600014

Hubble,J.P., Busenbark, K.L., \& Koller,W.C.(1989). Essentialtremor.ClinicalNeuropharmacology, 12(6), 453-482. doi: http://dx.doi.org/10.1097/00002826-198912000-00001

Jiménez-Jiménez, F. J., Alonso-Navarro, H., García-Martín, E., Lorenzo-Betancor, O., Pastor, P., \& Agúndez, J. A. (2013). Update on genetics of essential tremor. Acta Neurologica Scandinavica, 128(6): 359-371. doi: http://dx.doi.org/10.1111/ane.12148

Leite, M. A. A. (2010). Tremor Essencial. Revista Hospital Universitário Pedro Ernesto, 9(1), 20-28. Recuperado de http://www.e-publicacoes.uerj.br/index.php/revistahupe/article/ view/9030/6923

Medeiros, L. M. I., Castro, P. C. F., Felício, A. C., Queiros, B. B., Silva, S. M. C. A., Ferraz, H. B., . . Borges, V. (2016). Patients with essential tremor can have manual dexterity and attention deficits with no impairments in other cognitive functions. Arquivos de Neuro-Psiquiatria, 74(2), 122-127. doi:http://dx.doi.org/10.1590/0004-282X20160006

Moraes, B. T., \& de Biase, N. G. (2016). Laryngoscopy evaluation protocol for the differentiation of essential and dystonic voice tremor. Brazilian Journal of Otorhinolaryngology, 82(1), 88-96. doi:http://dx.doi.org/10.1016/j.bjorl.2015.11.001

Nasser, J. E., Falavigna, A., Alaminos, A., Bonatelli, A. P., \& Ferraz, F. (2002). Estimulação cerebral contínua (DBS) talâmica para controle do tremor. Arquivos de Neuro-Psiquiatria, 60(2), 429-434. doi:http://dx.doi.org/10.1590/S0004-282X2002000300017

Pereira, J. S., Pimentel, M. L. V., \& Nicaretta, D. H. (1993). Tremor essencial: Observações clínicas. Arquivos de Neuro-Psiquiatria, 51(3), 337-340. doi:http://dx.doi.org/10.1590/ S0004-282X1993000300008

Shah, B. (2017). Essential tremor: A comprehensive overview. Journal of Neurological Disorders, 5(3), 1-4. doi:http://dx.doi.org/10.4172/2329-6895.1000343 
Troiano, A. R., Teive, H. E. G., Fabiani, G. B., Zavala, J. A. A., Sá, D. S., Germiniani, F. M. B., . . . Werneck, L. C. (2004). Uso do propranolol de ação prolongada em 40 pacientes com tremor essencial e virgens de tratamento: Um ensaio clínico não controlado. Arquivos de NeuroPsiquiatria, 62(1), 86-90. doi:http://dx.doi.org/10.1590/S0004-282X2004000100015

Troster, A. I., Woods, S. P., Fields, J. A., Lyons, K. E., Pahwa, R., \& Higginson, C. I., \& Koller, C. (2002). Neuropsychological deficits in essential tremor: An expression of cerebellothalamo-cortical pathophysiology? European Journal of Neurology, 9(2), 143-51. doi:http://doi.org/10.1046/j.1468-1331.2002.00341.x

Zeigelboim, B. S., \& Mittelmann, C. (2008). Avaliação vestibular no tremor essencial. Revista CEFAC, 10(2), 233-237. doi:http://dx.doi.org/10.1590/S1516-18462008000200013

Recebido em: 26/04/2019

Última revisão: 09/09/2019

Aceite final: 16/09/2019

\section{Sobre as autoras:}

Alanny Nunes de Santana: Doutoranda em Psicologia Cognitiva pela Universidade Federal de Pernambuco (UFPE). Mestra em Psicologia Cognitiva pela UFPE. Graduada em Psicologia pela Universidade Federal de Campina Grande (UFCG). E-mail: alanny46@gmail.com, Orcid: http://orcid.org/0000-0001-9505-3508

Janaina Gaia Ribeiro Dias: Doutoranda em Psicologia Cognitiva pela Universidade Federal de Pernambuco (UFPE). Mestra em Psicologia pela UFPE. Especialista em Neuropsicologia Clínica Infantil pelo Centro Universitário CESMAC. Graduada em Psicologia pelo Centro Universitário CESMAC. E-mail: janainagrd.psi@gmail.com, Orcid: http://orcid.org/0000-0001-7825-9213 